\title{
A COMPARATIVE STUDY OF THE EARLY STAGES OF MERCURY, CADMIUM, LEAD, SILVER AND COPPER ELECTRODEPOSITION ON COLUMNAR AND SMOOTH PLATINUM ELECTRODES
}

\author{
M. E. Martins, R. C. Salvarezza and A. J. Arvia* \\ Instituto de Investigaciones Fisicoquíimicas Teóricas y Aplicadas (INIFTA), Sucursal 4, \\ Casilla de Correo 16, (1900) La Plata, Argentina
}

(Received 31 October 1995)

\begin{abstract}
The early stages of metal (M) electrodeposition $(\mathrm{M}=\mathrm{Cu}, \mathrm{Ag}, \mathrm{Pb}, \mathrm{Cd}$ and $\mathrm{Hg}$ ) on columnar and smooth Pt substrates (S) were investigated in acid solutions applying potentiodynamic techniques. At moderate and high potential scanning rates $\mathbf{M}$ electrodeposition on columnar substrates yields $\mathbf{M}$ domains which are dominated either by $\mathbf{M}-\mathbf{S}$ interactions (M-S domains) or $\mathbf{M}-\mathbf{M}$ interactions (M-M domains) as deduced from anodic stripping data. The roughness of $S$, the rate of surface diffusion of $M$ atoms and the exchange current density of the $\mathrm{M} / \mathrm{M}^{z+}$ electrode reaction have a remarkable influence on the growth mode of the $\mathbf{M}$ overlayer. Rearrangements involving $\mathbf{M}-\mathbf{S}$ and $\mathbf{M}-\mathbf{M}$ domains leading to equilibrium at the $M$ overlayer were deduced from voltammetric data. The rate of these rearrangements depends mainly on the surface diffusion of $\mathbf{M}$ atoms. Correlations between the charge related to $\mathbf{M}-\mathrm{S}$ domains and $\Delta H_{\mathrm{s}}$, the enthalpy of sublimation, and $T_{\mathrm{m}}$, the melting temperature of $\mathrm{M}$, were established. These parameters reflect the trend of $M$ atoms to participate in surface diffusion processes. Copyright $(\mathrm{O}$ 1996 Elsevier Science Ltd
\end{abstract}

Key words: metal electrodeposition, surface diffusion, electrode roughness, growth modes.

\section{INTRODUCTION}

In the early stages of metal (M) electrodeposition onto a homogeneous foreign substrate (S), the M-S binding energy (BE) plays an important role in determining the growth mode of the $M$ bulk phase[1-5]. For $\mathbf{M}-\mathrm{S}$ BE values lower than $\mathbf{M}-\mathbf{M}$ $B E$ values, bulk $M$ electrodeposition implies a relatively small surface concentration of $M$ adatoms, and then, the process can be described through condensation kinetics involving a number of successive steps leading to the formation of the condensed bulk phase via nucleation phenomena. Conversely, when the $\mathrm{M}-\mathrm{S} \mathrm{BE}$ is greater than the M-M BE, usually one or more monolayers of $\mathrm{Me}$ adatoms can be formed before bulk $M$ growth. In this case, the properties of deposited two-dimensional (2D) layers are strongly influenced by the crystallographic orientation of $\mathbf{S}$. The formation of a $2 \mathrm{D}$ layer also implies the possibility of other concurrent processes such as a 2D to 3D phase transition[6,7], and 2D and 3D alloy formation $[1,8]$. These processes have a considerable influence on the $M$ electrodeposition kinetics and mechanism, including the dynamics of the depositing particles itself leading to different $M$ deposit topographies and textures.

Recently reported data on $\mathrm{M}$ monolayer (ML) and multilayer growth on either different Pt single crystal

* Author to whom correspondence should be addressed. faces, polycrystalline, platinized $\mathrm{Pt}$, or columnar $\mathrm{Pt}$ electrodes (CPtE's)[1-16] have demonstrated that the initial stages of $M$ electrodeposition are influenced by the topography of $S$ both at the atomic level through the specific crystallographic structure of the substrate, and at the $\mathrm{nm}$ level through the surface irregularity of $S[14]$. In fact, the use of welldefined rough metal substrates allowed us to enhance the contribution of transport processes at the surface and inside the bulk of the substrate during $\mathbf{M}$ electrodeposition under non-equilibrium conditions leading to $\mathrm{M}-\mathrm{S}$ and $\mathrm{M}-\mathrm{M}$ domains. For this purpose the surface roughness, the potential sweep rate, and the $M$ ion concentration in the solution have to be adequately selected[17]. Accordingly, data on the formation of $\mathbf{M}-\mathbf{S}$ and $\mathbf{M}-\mathbf{M}$ domains on CPtE have shown that this type of substrate[1417] is adequate to attempt a comparative investigation of the influence of electrode surface irregularities on the early stages of $\mathbf{M}$ deposition leading to a surface coverage of $S$ by $M$ under either partial or complete non-equilibrium.

CPtE's can be easily prepared by in situ electroreduction of a hydrous $\mathrm{Pt}$ oxide layer[18]. The roughness factor $(R)$ of $\mathrm{CPtE}$ depends on both the amount of hydrous Pt oxide previously formed on the $\mathrm{Pt}$ substrate, and the rate of the hydrous $\mathrm{Pt}$ oxide layer electroreduction. This type of electrode exhibits a columnar microstructure with an average column height in the range $10-10000 \mathrm{~nm}$, a void to filled volume ratio of about 0.5 , and columns and 
intercolumnar voids about $10 \mathrm{~nm}$ in average diameter, as inferred from scanning tunneling microscopy (STM)[19], combined STM-scanning electron microscopy (SEM)[20, 21], ellipsometry[22], ultraviolet and visible electroreflectance spectroscopy[23], and electrochemical data[24, 25]. Each CPtE behaves as a rough polycrystalline Pt electrode with a nearly constant distribution of crystallographic orientations, regardless of the magnitude of $R$, at least in the range $1<R<10^{3}[18]$.

This work is devoted to a comparative study of the early stages of $\mathrm{Cu}, \Lambda \mathrm{g}, \mathrm{Pb}, \mathrm{Cd}$ and $\mathrm{Hg}$ electrodeposition at moderate and high potential scanning rates under non-equilibrium conditions on CPtE's and smooth $\mathrm{Pt}$ electrodes. The main concern of this work is to determine the influence of roughness on the formation of either continuous or discontinuous $\mathbf{M}-\mathbf{S}$ and $\mathbf{M}-\mathbf{M}$ domains on the substrate, possible surface rearrangements involving these domains, and the probable relation of these rearrangements to the surface diffusion of $\mathrm{M}$ atoms. This contribution to the overall $M$ electrodeposition kinetics can be enhanced by using CPtE's under moderate and fast potentiodynamic electrodeposition conditions.

\section{EXPERIMENTAL}

Electrochemical runs were made in a conventional three-electrode glass cell. Two types of Pt working electrodes were used, namely, smooth polycrystalline (pc) $\mathrm{Pt}$, and CPtE's with different values of $R$. A large $\mathrm{Pt}$ gauze was employed as a counter electrode, and a reversible hydrogen electrode (rhe) in the same acid solution was used as a reference. Potentials in the text are given on the rhe scale.

Smooth $\mathrm{Pt}$ electrodes were immersed first in hot $\mathrm{H}_{2} \mathrm{SO}_{4}+\mathrm{HNO}_{3}$ solution, then rinsed in Milli-Q* water, and finally placed in the same solution as that used in the electrochemical runs.

CPtE's were prepared following the procedure already described in the literature[18]. The apparent area of the initial Pt substrate was $0.06 \mathrm{~cm}^{2}$. CPtE's with values of $R$ ranging from 20 to 200 were prepared. The value of $R$ was determined by the $\mathrm{H}$ adatom electrosorption voltammetric charge as indicated elsewhere $[18,26]$. As already reported, roughness relaxation occurs on columnar metal electrodes[21]. All CPtE's were stabilized in $0.5 \mathrm{M}$ $\mathrm{H}_{2} \mathrm{SO}_{4}$ for $24 \mathrm{~h}$ prior to the electrochemical runs.

CPtE surface characterization was made by ex situ STM imaging with a Nanoscope III STM operating in air. STM tips were made from Pt-Ir Nanotips. STM measurements were performed using a $0.05-$ $0.10 \mathrm{~V}$ bias voltage with the tip $(+)$ at $1-2 \mathrm{nA}$ constant current. Different tips were used to discard occasional artifacts caused by the tip geometry. STM images were presented as raw data with only plane removal.

Metal electrodeposition/anodic stripping voltammetry was studied at $25^{\circ} \mathrm{C}$ using the following aqueous solutions: $0.5 \mathrm{M} \mathrm{H} \mathrm{H}_{2} \mathrm{SO}_{4}+10^{-3} \mathrm{M} \mathrm{CuSO}_{4}$ for $\mathrm{Cu}$ electrodeposition; $1 \mathrm{M} \mathrm{H}_{2} \mathrm{SO}_{4}+5 \times 10^{-4} \mathrm{M}$ $\mathrm{Ag}_{2} \mathrm{SO}_{4}$ for $\mathrm{Ag}$ electrodeposition; $1 \mathrm{M} \quad \mathrm{HClO}_{4}$ $+10^{-3} \mathrm{M} \mathrm{Pb}\left(\mathrm{ClO}_{4}\right)_{2}$ for $\mathrm{Pb}$ electrodeposition; $1 \mathrm{M}$ $\mathrm{H}_{2} \mathrm{SO}_{4}+10^{-3} \mathrm{M} \mathrm{CdSO}_{4}$ for $\mathrm{Cd}$ electrodeposition;
$0.5 \mathrm{M} \mathrm{HClO}_{4}+10^{-3} \mathrm{M} \mathrm{Hg}_{2}\left(\mathrm{NO}_{3}\right)_{2}$ for $\mathrm{Hg}$ electrodeposition. All solutions were prepared with analytical reagent grade chemicals and $M$ illi- $Q^{*}$ water. Runs were performed under continuous $\mathrm{N}_{2}$ saturation. The composition of each aqueous solution resulted from a compromise between the solubility of the $M$ salt and the use of a common anion for the acid and salt which allowed us to avoid as much as possible the interference of anion adsorption in the electrochemical reaction.

To follow the $M$ electrodeposition/anodic stripping processes conventional voltammetry was applied in the range $0.05-1.45 \mathrm{~V}$ at potential scan rates in the range $0.001 \mathrm{~V} \mathrm{~s}^{-1}<v<0.1 \mathrm{Vs}^{-1}$.

\section{RESULTS}

\subsection{S TM imaging of $\mathrm{Pt}$ substrates}

A knowledge of the substrate surface at the $\mathrm{nm}$ level is essential to discriminate those features in the voltammetric electrodeposition of $\mathbf{M}$ overlayers which can be attributed to the substrate topography.

The ex situ STM image $\left(100 \times 100 \mathrm{~nm}^{2}\right)$ of a smooth polycrystalline $\mathrm{Pt}$ substrate (Fig. 1) shows flat terraces of about $50 \times 50 \mathrm{~nm}^{2}$ in surface area with a corrugation a few atoms in height. These terraces are separated by steps of about 10 atoms high, the steps forming well defined angles.

The STM images $\left(100 \times 100 \mathrm{~nm}^{2}\right.$ and $\left.30 \times 30 \mathrm{~nm}^{2}\right)$ of a CPtE $(R \cong 30)($ Fig. $2 \mathrm{a}$, b) show a rough topography on two scales, namely, a broad columnar structure $10-20 \mathrm{~nm}$ in average size, and a fine cluster structure within each column, each cluster being about $2-5 \mathrm{~nm}$ in average size (Fig. 2c). The STM image at a high resolution $\left(8 \times 8 \mathrm{~nm}^{2}\right)$ (Fig. 2d) shows fine clusters exhibiting in some regions (Fig. 2d, on the left hand side of the image centre) hexagonal arrays of atoms with an interatomic distance $d=0.28 \mathrm{~nm}$ similar to the $\mathrm{Pt}-\mathrm{Pt}$ interatomic distance.

\subsection{Electrochemical data}

Metal $(\mathrm{M}=\mathrm{Cu}, \quad \mathrm{Ag}, \quad \mathrm{Hg}, \quad \mathrm{Cd}$ and $\mathrm{Pb})$ electrodeposition/anodic stripping voltammograms on CPtE (Figs 3-5) and smooth polycrystalline Pt (Fig. 6) were obtained under comparable conditions.

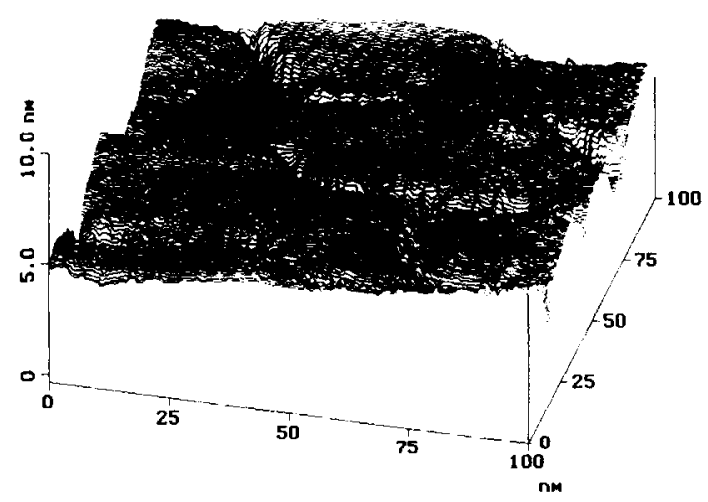

Fig. 1. Constant current $100 \times 100 \mathrm{~nm}^{2}$ STM image of the $P$ t substrate. 


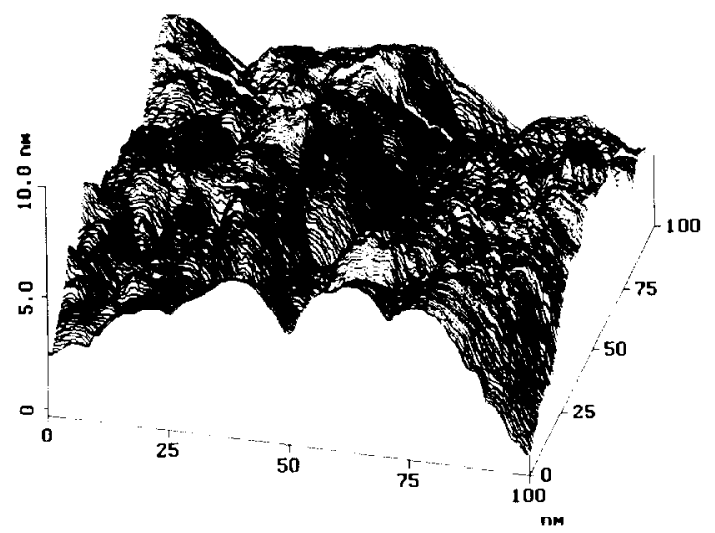

(a)

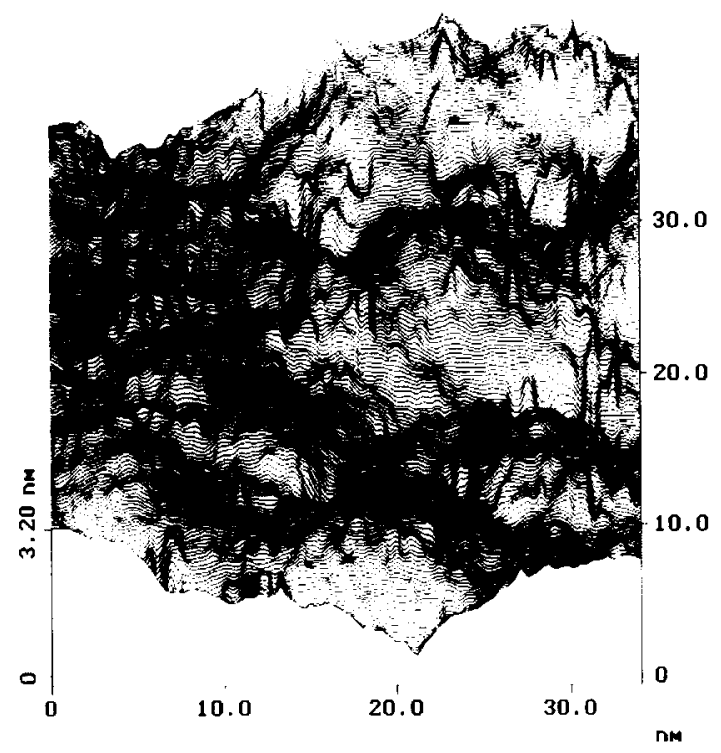

(b)

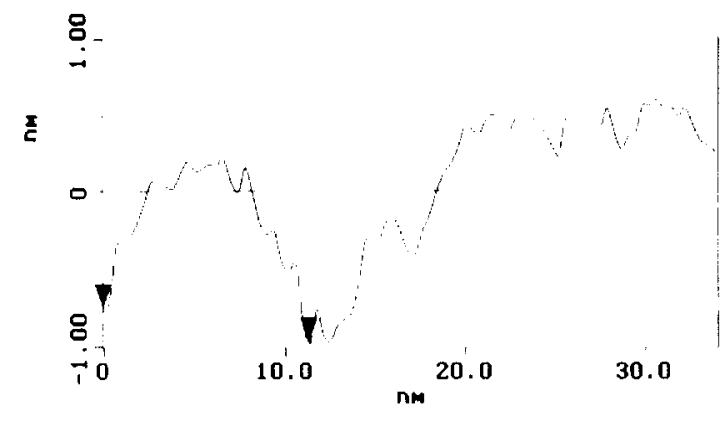

(c)

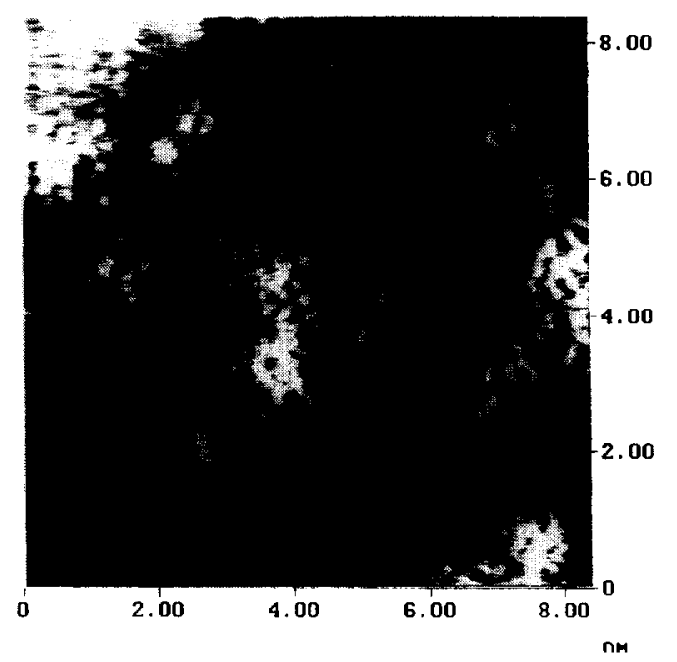

(d)

Fig. 2. (a) Constant current $100 \times 100 \mathrm{~nm}^{2} \mathrm{STM}$ image of a CPtE $(R=30)$; (b) $30 \times 30 \mathrm{~nm}^{2} \mathrm{STM}$ image showing the presence of the small clusters on the column surface; (c) cross-section of the STM image shown in Fig. $2 \mathrm{~b}$; (d) constant current $8 \times 8 \mathrm{~nm}^{2}$ STM image of a column domain showing the small clusters. Atomic resolution is observed in the middle of the left-hand side of the image.

For the sake of comparison, blank voltammograms were also systematically recorded (Fig. 7), particularly to establish possible ranges of potentials where interference of the $\mathbf{M}$ electrodeposition/anodic stripping reactions and the electrochemical reactions involving their own base solution constituents might occur. From all these voltammograms the following information can be derived for each system.

The $H$-electrosorption reactions occur in the range $0.05 \mathrm{~V}$ to $0.35 \mathrm{~V}$, and the $O$-electrosorption reactions take place in the range $0.80 \mathrm{~V}$ to $1.45 \mathrm{~V}[16]$. The potential ranges of these reactions remain the same irrespective of both $R$ and the base solution composition, although the shape of the voltammograms, as expected, depends on the solution composition. Under experimental conditions approaching equilibrium, ie $v \rightarrow 0$, with $\mathrm{M}$ electrodeposition on a smooth substrate involving a large $\mathrm{M}-\mathrm{S} B E$, the formation of $\mathrm{M}-\mathrm{S}$ domains ( $\mathrm{M}$ underpotential deposition) takes place within a range of potential in which $E>E_{\mathrm{r}}$, where $E_{\mathrm{r}}$ is the reversible potential of the $\mathrm{Me} / \mathrm{Me}^{z+}$ redox couple. Conversely, $\mathrm{M}$ electrodeposition yielding $\mathbf{M}-\mathbf{M}$ domains ( $\mathbf{M}$ overpotential deposition) occurs for $E<E_{\mathrm{r}}$.

The same processes described above take place on CPtE's. The anodic stripping voltammogram resulting from $\mathrm{Cu}$ electrodeposition $\left(E_{\mathrm{r}}=0.25 \mathrm{~V}\right)$ (Fig. 3a), shows peak IIIa related to the electrodissolution of the $\mathbf{M}-\mathbf{M}$ domains involving the apparent charge density $q_{M-M}$, and peaks IIa, I'a and Ia related to the electrodissolution of the $M-S$ domains involving an apparent charge density $q_{\mathrm{M}-\mathrm{s}}$. The values of $q_{M-S}$ and $q_{M-M}$ are derived from the integration of the corresponding voltammetric current peaks. The $O$-electrosorption on $\mathrm{Pt}$ takes place in the range $0.85 \mathrm{~V} \leqslant E \leqslant 1.45 \mathrm{~V}$ (peak IVa).

For $\mathrm{M}=\mathrm{Ag}$ in $5 \times 10^{-4} \mathrm{M} \mathrm{Ag}_{2} \mathrm{SO}_{4}\left(E_{\mathrm{r}}=0.62 \mathrm{~V}\right)$, and $\mathrm{M}=\mathrm{Hg}$ in $10^{-3} \mathrm{M} \mathrm{Hg}_{2}\left(\mathrm{NO}_{3}\right)_{2}\left(E_{\mathrm{r}}=0.70 \mathrm{~V}\right)$, 


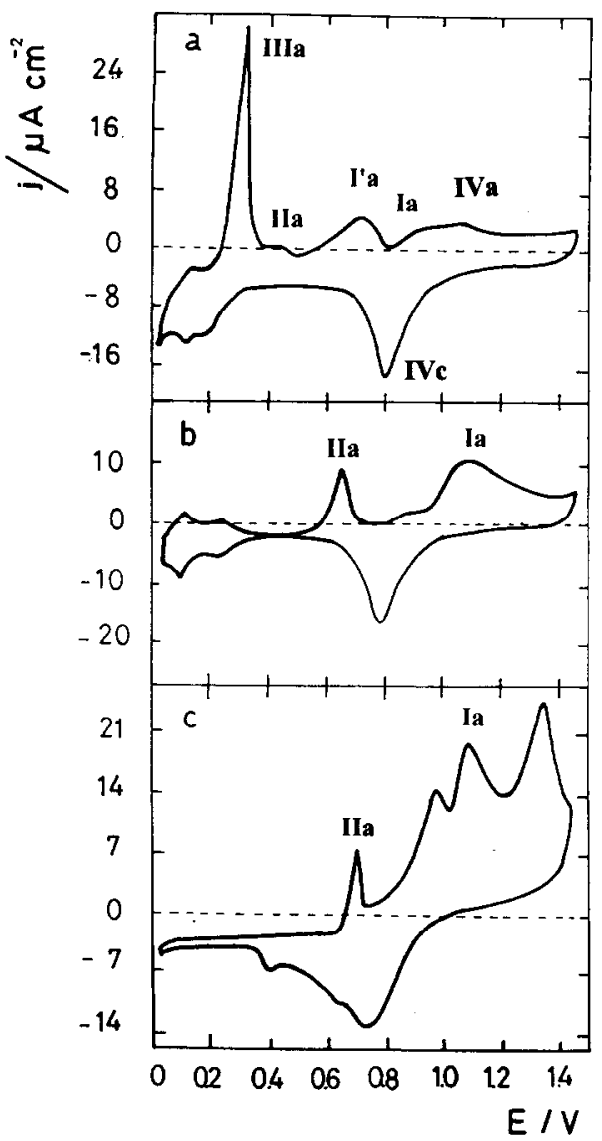

Fig. 3. Voltammograms related to the electrodeposition and anodic stripping of metals on CPtEs. $R=30$; $v=5 \times 10^{-3} \mathrm{~V} \mathrm{~s}^{-1} ; 25^{\circ} \mathrm{C}$. (a) $\mathrm{Cu}$ in $0.5 \mathrm{M} \mathrm{H}_{2} \mathrm{SO}_{4}+10^{-3} \mathrm{M}$ $\mathrm{CuSO}_{4}$; (b) $\mathrm{Ag}$ in $1.0 \mathrm{M} \mathrm{H}_{2} \mathrm{SO}_{4}+5 \times 10^{-4} \mathrm{M} \mathrm{Ag}_{2} \mathrm{SO}_{4}$; (c) $\mathrm{Hg}$ in $0.5 \mathrm{M} \mathrm{HClO}_{4}+10^{-3} \mathrm{M} \mathrm{Hg}_{2}\left(\mathrm{NO}_{3}\right)_{2}$.

peak IIa is related to the electrodissolution of the $\mathbf{M}-\mathbf{M}$ domains, and peak Ia comprises both the electrodissolution of $\mathrm{M}-\mathrm{S}$ domains and the commencement of the $O$-electroadsorption at free Pt sites. Peak IVa is principally related to the $O$-electroadsorption. In this case, the evaluation of the apparent charge density related to $q_{\mathrm{M} s}$ from peak Ia requires the previous determination from the blank of the $O$ electroadsorption charge.

For $\mathbf{M}=\mathbf{P b}$ and $\mathbf{M}=\mathbf{C d}$, the $\mathbf{M}-\mathbf{M}$ domain formation/anodic stripping processes overlap to a large extent with the potential range of the hydrogen evolution reaction (HER), as for the $\mathrm{M}^{2+}$ ion concentration in solution at $25^{\circ} \mathrm{C}, E_{\mathrm{r}}=-0.214 \mathrm{~V}$ for $\mathrm{Pb} / 10^{-3} \mathrm{M} \mathrm{PB}^{2+}$ and $E_{\mathrm{r}}=-0.491 \mathrm{~V}$ for $\mathrm{Cd} / 10^{-3} \mathrm{M}$ $\mathrm{Cd}^{2+}[27]$.

The electrodissolution of $\mathrm{Cd}$ and $\mathrm{Pb}$ deposits occurs in the double layer region of $\mathrm{Pt}$, and the $O$ electrosorption takes place at $E>0.85 \mathrm{~V}$. Then, only values of $q_{\mathrm{M}-\mathrm{S}}$ can be obtained as the value of $q_{\mathrm{M}-\mathrm{M}}$ is strongly disturbed by the hydrogen evolution reaction itself.

At constant $R$, the contributions of the $H$ - and $O$ electrosorption processes on CPtE's are gradually diminished as $v$ is decreased, in contrast to the electrodeposition reaction yielding $\mathbf{M}-\mathbf{M}$ domains (Figs 3-5).

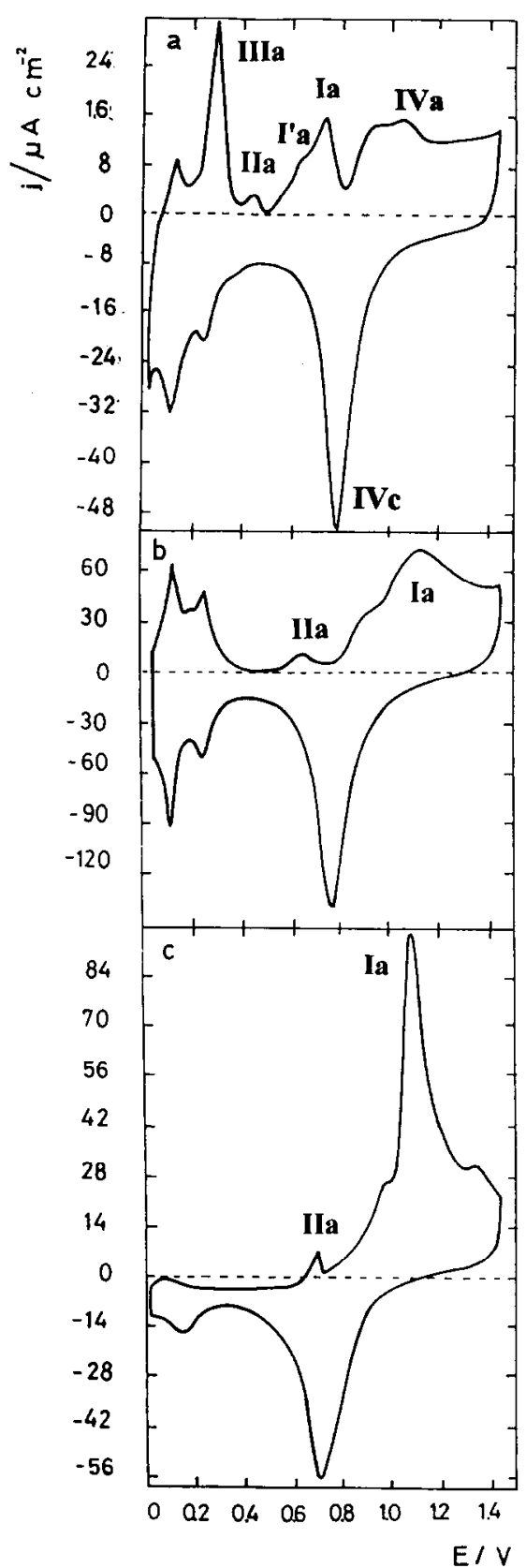

Fig. 4. Voltammograms related to the electrodeposition and anodic stripping of metals on CPtEs. $R=30$; $v=2 \times 10^{-2} \mathrm{~V} \mathrm{~s}^{-1} ; 25^{\circ} \mathrm{C}$. (a) $\mathrm{Cu}$ in $0.5 \mathrm{M} \mathrm{H}_{2} \mathrm{SO}_{4}+10^{-3} \mathrm{M}$ $\mathrm{CuSO}_{4}$; (b) $\mathrm{Ag}$ in $1.0 \mathrm{M} \mathrm{H}_{2} \mathrm{SO}_{4}+5 \times 10^{-4} \mathrm{M} \mathrm{Ag}_{2} \mathrm{SO}_{4}$; (c) $\mathrm{Hg}$ in $0.5 \mathrm{M} \mathrm{HClO}_{4}+10^{-3} \mathrm{M} \mathrm{Hg}_{2}\left(\mathrm{NO}_{3}\right)_{2}$.

At constant $v$, as $R$ decreases the voltammetric characteristics of the electrochemical processes become closer to those found at constant $R$ by decreasing $v$, and vice versa.

In general, the voltammograms resulting from CPtE's run at a moderate or a fast potential scanning show that the $\mathrm{M}-\mathrm{S}$ domain formation can be shifted negatively, overlapping partially the potential range where the formation of the $\mathbf{M}-\mathbf{M}$ domains takes place, yielding a substrate which is either partially or completely covered by a deposit. The rela- 


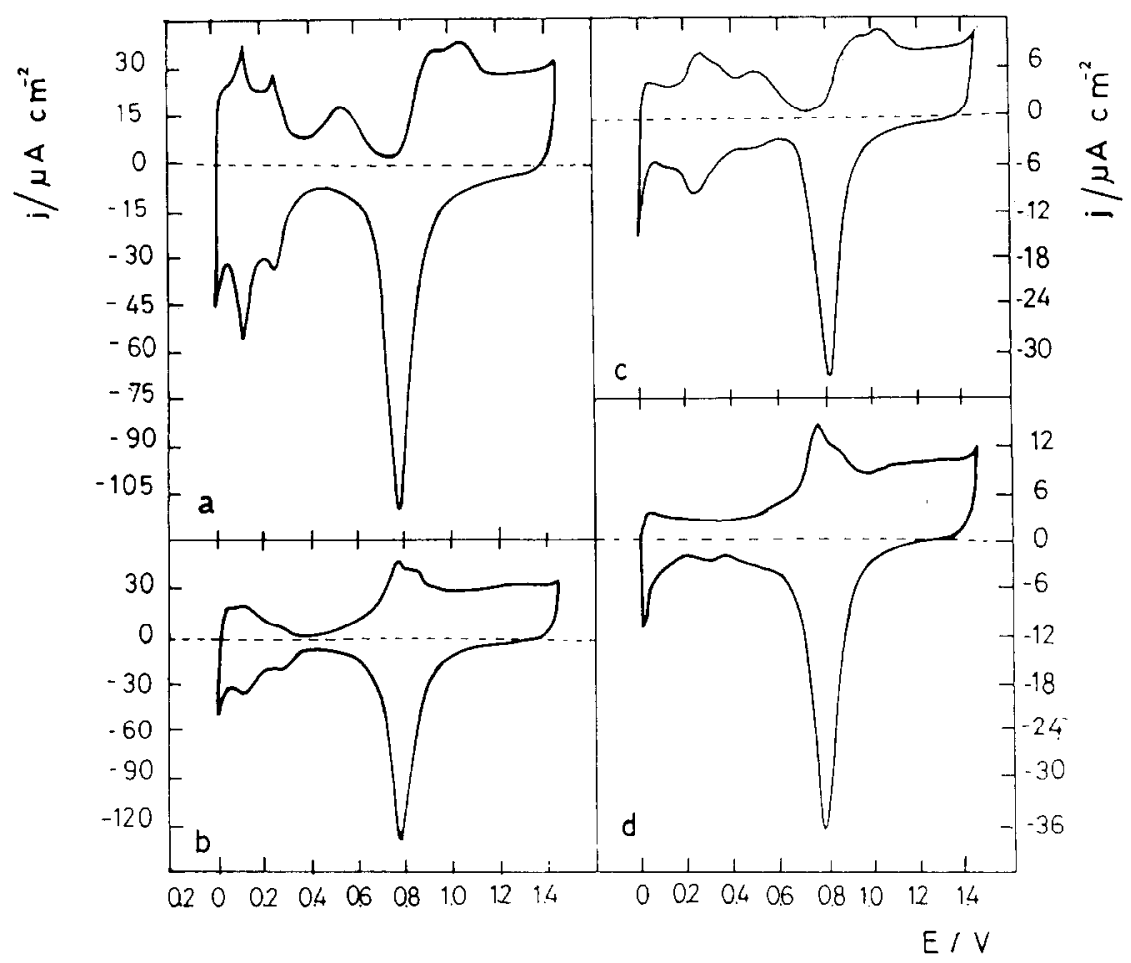

Fig. 5. Voltammograms related to the electrodeposition and anodic stripping of metals on $\mathrm{CPtEs}$. $R=30 ; v=5 \times 10^{-3} \mathrm{~V} \mathrm{~s}^{-1}$ (c, d) $; v=2 \times 10^{-2} \mathrm{~V} \mathrm{~s}^{-1}$ (a, b); $25^{\circ} \mathrm{C}$. (a, c) Cd in $1.0 \mathrm{M} \mathrm{H}_{2} \mathrm{SO}_{4}+10^{-3} \mathrm{M}$ $\mathrm{CdSO}_{4} ;(\mathrm{b}, \mathrm{d}) \mathrm{Pb}$ in $\left.1.0 \mathrm{M} \mathrm{HClO}_{4}+10^{-3} \mathrm{M} \mathrm{Pb}_{(\mathrm{ClO}}\right)_{2}$.

tive amount of material related to the $\mathrm{M}-\mathrm{S}$ and $\mathbf{M}-\mathbf{M}$ domains can be estimated from anodic stripping voltammetric data for both smooth $\mathrm{Pt}$ and CPtE's. These data are assembled in Table 1, where $N_{\mathrm{M}-\mathrm{S}}=q_{\mathrm{M}-\mathrm{S}} / z F$ and $N_{\mathrm{M}-\mathrm{M}}=q_{\mathrm{M}-\mathrm{M}} / z F$, where $N_{\mathrm{M}-\mathrm{S}}$ and $N_{\mathrm{M}-\mathrm{M}}$ are the number of moles per unit of apparent substrate area related to the $\mathbf{M}-\mathbf{S}$ and $\mathbf{M}-\mathbf{M}$ domains, respectively, $\boldsymbol{z}$ is the valency of the $\mathrm{M}^{z+}$ ion, and $F$ is the Faraday constant.

A correlation between electrochemical data and properties of the Me deposit was made by plotting both the $N_{\mathrm{M}-\mathrm{s}}$ vs. $T_{\mathrm{m}}$ and $N_{\mathrm{M}-\mathrm{M}}$ vs. $T_{\mathrm{m}}$, where $T_{\mathrm{m}}$ is the melting temperature of bulk $M$ in $K$ (Fig. 8), and the $N_{\mathrm{M}-\mathrm{s}}$ vs. $\Delta H_{\mathrm{s}}$ and $N_{\mathrm{M}-\mathrm{M}}$ vs. $\Delta H_{\mathrm{s}}$ (Fig. 9), $\Delta H_{\mathrm{s}}$ being the enthalpy of sublimation of $\mathrm{M}$. Values of $T_{\mathrm{m}}$ and $\Delta H_{\mathrm{s}}$ were taken as parameters reflecting the surface mobility of $\mathrm{M}$ atoms[28-34]. Values of $\Delta H_{\mathrm{s}}$ were calculated from $\Delta H_{\mathrm{v}}$, the enthalpy of vaporization, and $\Delta H_{\mathrm{f}}$, the enthalpy of fusion of $\mathrm{M}$ (Table 2) $[27,35]$. The bulk crystallographic structure of
M's was also included in Table 2[27]. At constant $R$ and $v$, a decay of $N_{\mathrm{M}-\mathrm{S}}$ with both $T_{\mathrm{m}}$ (Fig. 5a) and $\Delta H_{\mathrm{s}}$ (Fig. 9) can be observed. In contrast, for $T_{\mathrm{m}}<$ $1200 \mathrm{~K}$, the $N_{\mathrm{M}-\mathrm{M}}$ vs. $T_{\mathrm{m}}$ plot (Fig. 8b) exhibits a positive slope which becomes much steeper for $T_{\mathrm{m}}>$ $1200 \mathrm{~K}$. Furthermore, the value of $N_{\mathrm{M}-\mathrm{s}}$ rises as $v$ is diminished, but $\Delta N_{\mathrm{M}-\mathrm{S}}$, the change in $N_{\mathrm{M}-\mathrm{S}}$ resulting from two values of $v$, decreases as $T_{\mathrm{m}}$ increases. In principle, these results suggest a substantial influence of $v$ on the M electrodeposition on CPtE's, ie a relevant role played by the non-equilibrium conditions prevailing at the reaction interface caused by the specific topographic features of CPtEs influenced by $v$.

\section{DISCUSSION}

For those systems in which the M-S exceeds the $M-M \quad B E$, the early stages of $M$ electrodeposition can produce either complete or incomplete $\mathrm{M}-\mathrm{S}$

Table 1. Values of $N_{\mathrm{M}-\mathrm{S}}$ and $N_{\mathrm{M}-\mathrm{M}}$ obtained at different values of $v$ and $R$ at $298 \mathrm{~K}$

\begin{tabular}{|c|c|c|c|c|c|c|c|}
\hline \multirow[b]{2}{*}{$\mathbf{M}$} & \multirow[b]{2}{*}{$\begin{array}{l}E_{\mathrm{r}} \\
\mathrm{V}\end{array}$} & \multicolumn{2}{|c|}{$\begin{array}{c}v=5 \times 10^{-3} \mathrm{Vs}^{-1} \\
R=30\end{array}$} & \multicolumn{2}{|c|}{$\begin{array}{c}v=2 \times 10^{-2} \mathrm{Vs}^{-1} \\
R=30\end{array}$} & \multicolumn{2}{|c|}{$\begin{array}{c}v=2 \times 10^{-2} \mathrm{Vs}^{-1} \\
R=1.5\end{array}$} \\
\hline & & $\begin{array}{c}N_{\mathrm{M}-\mathrm{M}} \\
\mathrm{mol} \mathrm{cm}^{-2}\end{array}$ & $\begin{array}{c}N_{\mathrm{M}-\mathrm{s}} \\
\mathrm{mol} \mathrm{cm}^{-2}\end{array}$ & $\begin{array}{c}N_{\mathrm{M}-\mathrm{M}} \\
\mathrm{mol} \mathrm{cm}^{-2}\end{array}$ & $\begin{array}{c}N_{\mathrm{M}-\mathrm{s}} \\
\mathrm{mol} \mathrm{cm}^{-2}\end{array}$ & $\begin{array}{c}N_{\mathrm{M}-\mathrm{M}} \\
\mathrm{mol} \mathrm{cm}^{-2}\end{array}$ & 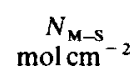 \\
\hline $\mathrm{Hg}$ & 0.704 & $9.1 \times 10^{-10}$ & $4.6 \times 10^{-9}$ & $3.0 \times 10^{-10}$ & $3.2 \times 10^{-9}$ & $5.1 \times 10^{-9}$ & $1.0 \times 10^{-8}$ \\
\hline $\mathrm{Cd}$ & -0.491 & - & $2.8 \times 10^{-9}$ & - & $2.0 \times 10^{-9}$ & - & $7.4 \times 10^{-9}$ \\
\hline $\mathrm{Pb}$ & -0.214 & - & $2.4 \times 10^{-9}$ & - & $1.9 \times 10^{-9}$ & - & $7.2 \times 10^{-9}$ \\
\hline $\mathrm{Ag}$ & 0.604 & $1.1 \times 10^{-9}$ & $1.3 \times 10^{-9}$ & $6.2 \times 10^{-10}$ & $1.0 \times 10^{-9}$ & $1.8 \times 10^{-9}$ & $5.2 \times 10^{-9}$ \\
\hline $\mathrm{Cu}$ & 0.249 & $4.2 \times 10^{-9}$ & $8.3 \times 10^{-10}$ & $2.7 \times 10^{-9}$ & $7.2 \times 10^{-10}$ & $1.5 \times 10^{-8}$ & $3.1 \times 10^{-9}$ \\
\hline
\end{tabular}




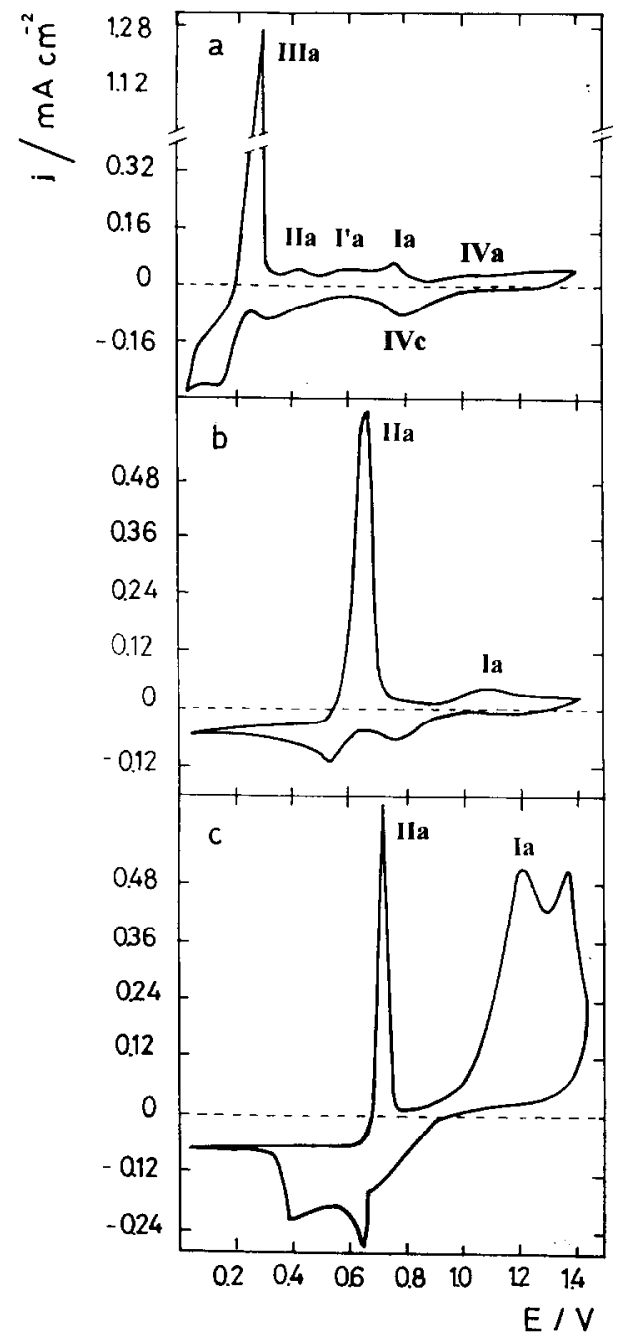

Fig. 6. Voltammograms related to the electrodeposition and anodic stripping of metals on smooth Pt. $v=2 \times 10^{-2} \mathrm{Vs}^{-1} ; 25^{\circ} \mathrm{C}$. (a) $\mathrm{Cu}$ in $0.5 \mathrm{M} \mathrm{H}_{2} \mathrm{SO}_{4}+10^{-3} \mathrm{M}$ $\mathrm{CuSO}_{4}$; (b) $\mathrm{Ag}$ in $1.0 \mathrm{M} \mathrm{H}_{2} \mathrm{SO}_{4}+5 \times 10^{-4} \mathrm{M} \mathrm{Ag}_{2} \mathrm{SO}_{4}$; (c) $\mathrm{Hg}$ in $0.5 \mathrm{M} \mathrm{HClO} \mathrm{H}_{4}+10^{-3} \mathrm{M} \mathrm{Hg}_{2}\left(\mathrm{NO}_{3}\right)_{2}$; (d) $\mathrm{Pb}$ in $1.0 \mathrm{M}$ $\mathrm{HClO}_{4}+10^{-3} \mathrm{M} \mathrm{Pb}\left(\mathrm{ClO}_{4}\right)_{2} ;$ (e) Cd in $1.0 \mathrm{M} \mathrm{H}_{2} \mathrm{SO}_{4}$ $+10^{-3} \mathrm{MCdSO}_{4}$.

domains followed by the growth of bulk $\mathbf{M}$ over those domains. When the $\mathbf{M}$ electrodeposition occurs on a well-defined and smooth substrate at a low potential scanning, the deposit approaches equilibrium conditions and a complete $\mathbf{M}-\mathrm{S}$ monolayer is built before $\mathbf{M}-\mathbf{M}$ domains begin to be formed. This situation has been extensively investigated for a number of systems[36-40]. In contrast, when the $M$ electrodeposition takes place on an irregular substrate at either moderate or fast potential scanning, an $\mathbf{M}$ deposit involving incomplete $\mathbf{M}-\mathbf{S}$ and $\mathbf{M}-\mathbf{M}$ domains far from equilibrium may result. Under these circumstances, structural rearrangements leading to equilibrium at the deposit level are favoured. These types of surface rearrangements are strongly enhanced by an appropriate selection of the substrate topography, as is the case of CPtE's.

For a given concentration of $\mathrm{M}^{2+}$ ions in the solution, the experimental results suggest a rearrangement of the $M$ deposit involving a change from

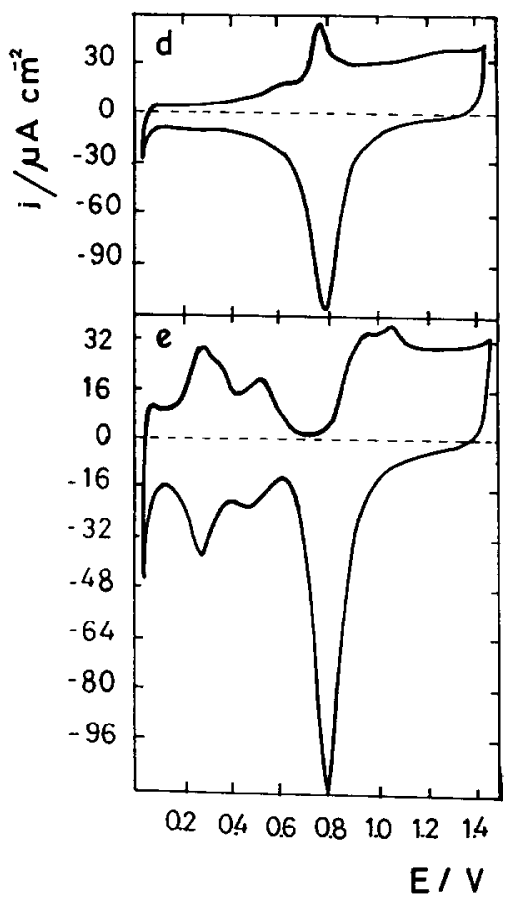

Fig. 6.-Continued

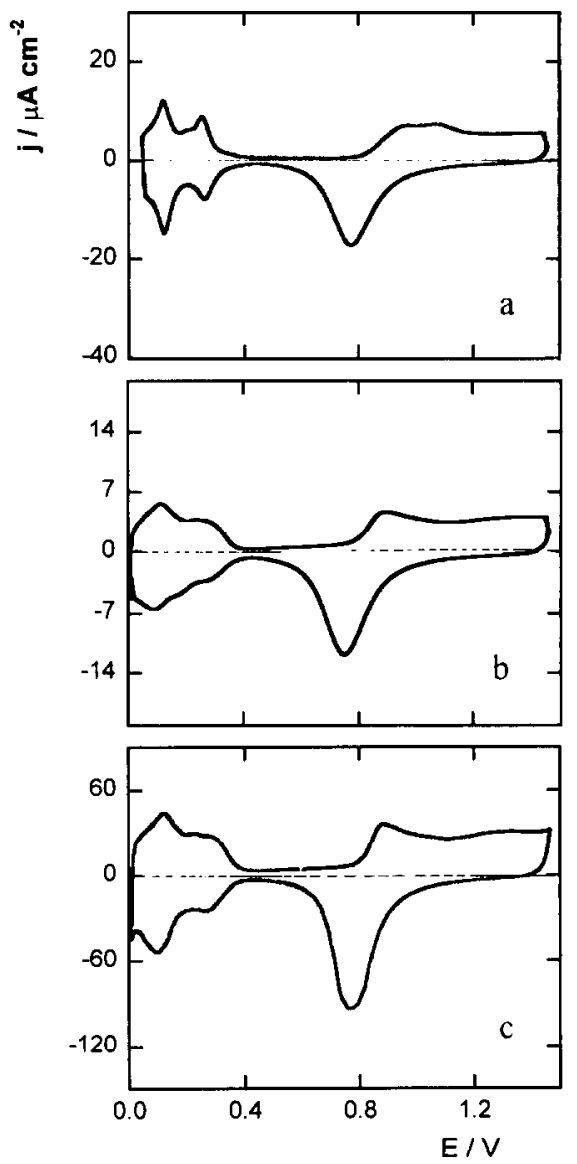

Fig. 7. Voltammograms (blanks) obtained on smooth $\mathrm{Pt}$. $v=5 \times 10^{-3} \mathrm{Vs}^{-1}$. $25^{\circ} \mathrm{C}$. (a) $1 \mathrm{M} \mathrm{H}_{2} \mathrm{SO}_{4}$; (b) $0.5 \mathrm{M} \mathrm{HClO}_{4}$ $+10^{-3} \mathrm{M} \mathrm{KNO}_{3} ;$ (c) $0.5 \mathrm{M} \mathrm{HClO}_{4}$. 

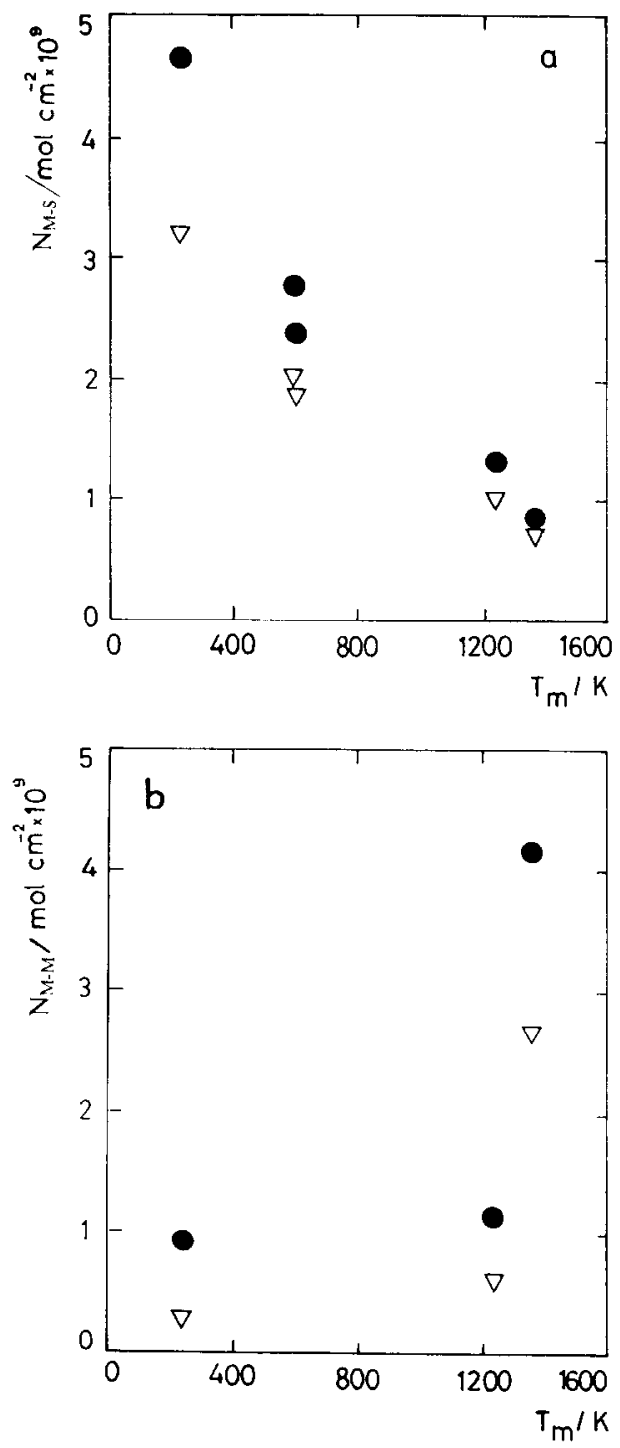

Fig. 8. (a) $N_{\mathrm{M}-\mathrm{s}}$ vs. $T_{\mathrm{m}}$ plot. $R=30$; (O) $v=5 \times$ $10^{-3} \mathrm{~V} \mathrm{~s}^{-1} ;(\nabla) v=2 \times 10^{-2} \mathrm{Vs}^{-1}$. (b) $N_{\mathrm{M}-\mathrm{M}}$ vs. $T_{\mathrm{m}}$ plot. $R=30 ;(\dot{O}) v=5 \times 10^{-3} \mathrm{Vs}^{-1} ;(\nabla) v=2 \times 10^{-2} \mathrm{Vs}^{-1}$.

M-M to M-S domains. The extent of this type of rearrangement at the surface depends on $v$ and $R$. Accordingly, for both smooth electrode and CPtE the electrodeposition of $\mathbf{M}$ atoms commences at more positive potentials than $E_{\mathrm{r}}$ leading to underpotential deposition (upd) domains.

However, when the electrode topography is rough as in CPtE's and the process occurs at a relatively high $v, \mathbf{M}$ upd occurs preferentially at the tips of the columnar structure. It should be noted that the number of $\mathbf{M}^{2+}$ ions at pores of the CPtE structure under voltammetric conditions rapidly tends to zero. In fact, for pores $5 \times 10^{-5} \mathrm{~cm}$ in average length, and $10^{-6} \mathrm{~cm}$ in average width, and $10^{-3} \mathrm{M} \mathrm{M}^{z+}$-ion concentration in the solution, the estimated number of $\mathrm{Me}$ ions within the pores is close to $10[16]$. Taking into account the relatively high value of the exchange current density of the $\mathbf{M} / \mathbf{M}^{z+}$ electrode reaction for $\mathrm{M}=\mathrm{Hg}, \mathrm{Pb}, \mathrm{Ag}, \mathrm{Cu}$ and $\mathrm{Cd}[41]$, the nil concentration of $\mathbf{M}^{z+}$ ions at pores is rapidly

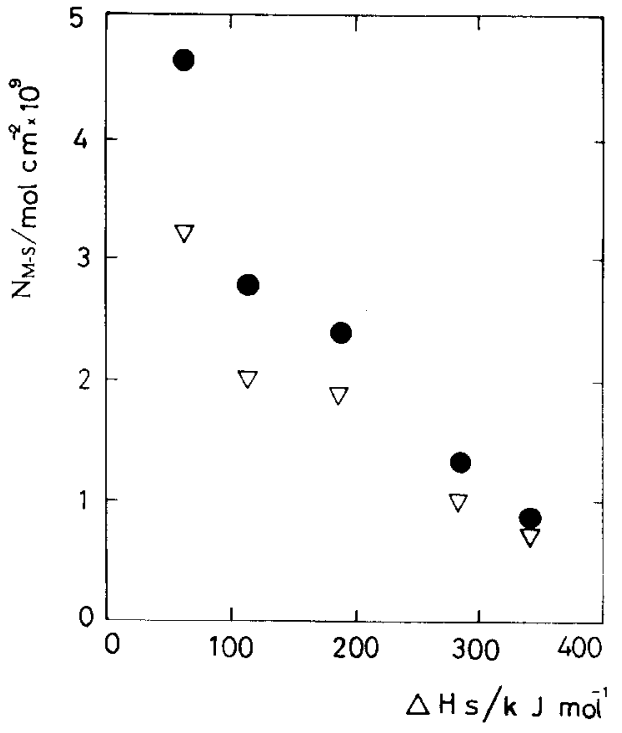

Fig. 9. $N_{\mathrm{M} \mathrm{s}}$ vs. $\Delta H_{\mathrm{s}}$ plot. $R=30 ;(0) v=5 \times 10^{-3} \mathrm{Vs}^{-1}$; $(\nabla) v=2 \times 10^{-2} \mathrm{Vs}^{-1}$.

attained during the cathodic potential scan. Therefore, under these conditions $M$ electrodeposition at pores is largely hindered and then the CPtE becomes only partially covered by $\mathbf{M}-\mathbf{S}$ domains as the applied potential reaches $E_{\mathrm{r}}$. Conversely, for $E<E_{\mathrm{r}}$ the growth of $\mathbf{M}$ domains takes place preferentially at column tips where $\mathbf{M}-\mathbf{S}$ domains have already been formed. Then, at the initial stages of $M$ overpotential deposition (opd), rather large uncovered substrate domains exist, particularly located at the walls and bottoms of columns. The presence of these uncovered domains is deduced from the existence of electroadsorbed $\mathrm{H}$ atoms in the voltammograms. The result of the overall deposition process is the appearance of a heterngeneously covered substrate under non-equilibrium conditions. Then, the formation of $\mathrm{M}-\mathrm{S}$ covered domains within the pores has to occur preferentially by a surface transport process involving $\mathrm{M}$ electrodeposited species.

The preceding description implies that a concentration gradient of $\mathbf{M}$ atoms is established between $\mathbf{M}-\mathbf{M}$ domains at column tips and uncovered substrate areas. This driving force assists a displacement (flux) of $\mathbf{M}$ atoms from $\mathbf{M}$-M domains at tip sites downwards. This means that a spilling of $\mathbf{M}$ atoms on the surface is produced to attain full coverage of the rough substrate by $\mathrm{M}-\mathrm{S}$, as expected for the equilibrium conditions at a smooth substrate[15].

Table 2. Values of $T_{\mathrm{m}}, \Delta H_{\mathrm{f}}, \Delta H_{\mathrm{v}}, \Delta H_{\mathrm{s}}$ and $\Delta H_{\mathrm{s}} / T_{\mathrm{m}}$ taken from the literature $[27,28]$ for the different electrodeposited metals

\begin{tabular}{cccccc}
\hline $\mathrm{M}$ & $\begin{array}{c}T_{\mathrm{m}} \\
\mathrm{K}\end{array}$ & $\begin{array}{c}\Delta H_{\mathrm{f}} \\
\mathrm{kJ} \mathrm{mol}^{-1}\end{array}$ & $\begin{array}{c}\Delta H_{\mathrm{v}} \\
\mathrm{kJ} \mathrm{mol}^{-1}\end{array}$ & $\begin{array}{c}\Delta H_{\mathrm{s}} \\
\mathrm{kJ} \mathrm{mol}^{-1}\end{array}$ & $\begin{array}{c}\Delta H_{\mathrm{s}} T_{\mathrm{m}} \\
\mathrm{J} \mathrm{mol}^{-1} \mathrm{~K}\end{array}$ \\
\hline $\mathrm{Hg}^{*}$ & 234 & 2.33 & 59.11 & 61.44 & 0.25 \\
$\mathrm{Cd}^{\dagger}$ & 594 & 6.20 & 106.76 & 112.96 & 0.19 \\
$\mathrm{~Pb}^{*}$ & 601 & 4.81 & 179.50 & 184.31 & 0.31 \\
$\mathrm{Ag}^{*}$ & 1234 & 11.00 & 274 & 285 & 0.23 \\
$\mathrm{Cu}^{*}$ & 1358 & 13.15 & 327 & 340.15 & 0.25 \\
$\mathrm{Pt}^{*}$ & 2028 & 22.43 & 520 & 542.43 & 0.27 \\
\hline
\end{tabular}

* fcc metals; † hcp metal. 
Therefore, further $\mathbf{M}$ atom capture at $\mathbf{M}$ covered tips appears to be followed by a surface diffusion of $\mathbf{M}$ atoms, either over $\mathbf{M}-\mathbf{S}$ or $\mathbf{M}-\mathbf{M}$ covered domains, or over the bare substrate for low M-S BE, leading to the completion of the $\mathrm{M}$ monolayer on the CPtE. Furthermore, before the completion of the ML is attained, either reversible or irreversible surface rearrangements could also appear as side processes.

The kinetics of $M$ surface rearrangements depends strongly on the mobility of $M$ atoms at the surface in a given environment[28-31, 34]. The experimental evidence for the participation of surface atom diffusion during electrodeposition is provided by the $N_{\mathrm{M}-\mathrm{s}}$ vs. $T_{\mathrm{m}}$ and $N_{\mathrm{M}-\mathrm{s}}$ vs. $\Delta H_{\mathrm{s}}$ plots (Figs 8 and 9), as the value of $D_{\mathrm{s}}$ can be expressed in terms of the relative $T_{\mathrm{m}} / T$ ratio by the equation[32]:

$$
\begin{aligned}
D_{\mathrm{s}}= & 740 \times 10^{-4} \exp \left[-30 T_{\mathrm{m}} / R T\right] \\
& +0.0140 \times 10^{-4} \exp \left[-13 T_{\mathrm{m}} / R T\right]
\end{aligned}
$$

where $D_{s}$ is the surface diffusion coefficient of $M$ in $\mathrm{m}^{2} \mathrm{~s}^{-1}, T_{\mathrm{m}}$ is the melting temperature of $\mathrm{M}$ in $\mathrm{K}, T$ is the working temperature in $\mathrm{K}$, and $R$ is the universal gas constant in cal $\mathrm{K}^{-1} \mathrm{~mol}^{-1}$. In addition, for $\mathbf{M}$ such as $\mathrm{Cu}, \mathrm{Ag}, \mathrm{Pb}$ and $\mathrm{Hg}$, it has been found[32, 33] that $\Delta H_{\mathrm{s}}$ and $T_{\mathrm{m}}$ are related through the empirical equation,

$$
\Delta H_{\mathrm{s}}=56 T_{\mathrm{m}}
$$

where $\Delta H_{\mathrm{s}}$ is given in cal mol${ }^{-1}$ and $T_{\mathrm{m}}$ in $\mathrm{K}$. The energy involved in the surface diffusion of $M$ atoms is a fraction of the energy related to a vapour-solid phase change $[42,43]$. After considering equation (2), equation (1) can also be written as follows

$$
\begin{aligned}
D_{\mathrm{s}}= & 740 \times 10^{-4} \exp \left[-0.54 \Delta H_{\mathrm{s}} / R T\right] \\
& +0.014 \times 10^{-4} \exp \left[-0.24 \Delta H_{\mathrm{s}} / R T\right]
\end{aligned}
$$

The $\mathbf{M}-\mathbf{S}$ domain to $\mathbf{M}-\mathbf{M}$ domain surface rearrangement on a rough substrate is a complicated process which in a first approach can be basically interpreted through a mechanism based on the surface diffusion of $\mathbf{M}$ atoms. For this purpose, let us assume that in the absence of covered domains at pores, $\langle v\rangle$, the average flux of $\mathrm{M}$ surface atoms from $\mathbf{M}-\mathbf{M}$ domains to bare substrate domains, is proportional to the rate of change in $q_{\mathrm{M}-\mathrm{s}}$. Then, the following proportionality can be written,

$$
\langle v\rangle \propto \mathrm{d} q_{\mathrm{M}-\mathrm{s}} / \mathrm{d} t
$$

Accordingly, taking into account the surface topography at small clusters forming the column tips as derived from STM imaging (Fig. 2c), and further assuming that the wall of columns is as smooth as the small cluster surface at column tips, it is reasonable to reduce the problem of surface diffusion of $\mathbf{M}$ atoms at these domains to the solution of Fick's law applied to isotropic surface diffusion on a smooth plane [44, 45]. Then, equation (4) expressing the average unidirectional flux of $\mathbf{M}$ atoms from $3 D M$ to bare domain, can be written as

$$
v=D_{\mathrm{s}} \mathrm{d}^{2} c_{\mathrm{M}} / \mathrm{d} x^{2}
$$

where $\mathrm{d}^{2} c_{M} / \mathrm{d} x^{2}$ defines the change in the concentration gradient of $M$ atoms in the $x$-direction at the smooth surface. Thus, equation (5) makes it possible to estimate from experimental data $\left\langle\Delta^{2} c_{M} / \Delta x^{2}\right\rangle_{\Delta t}$, the average value of $\mathrm{d}^{2} c_{\mathrm{M}} / \mathrm{d} x^{2}$ for the constant period of time involved in the voltammetric scan, taking $D_{\mathrm{s}}$ values estimated from equations $(1-3)$. From the extrapolation to $\Delta t \Rightarrow 0$ ie for $v \Rightarrow \infty$, it results that $\left\langle\Delta^{2} c_{M} / \Delta x^{2}\right\rangle_{\Delta t} \Rightarrow d^{2} c_{M} / d x^{2}$. For every $M$ these figures which are assembled in Table 3, are useful to explore the possible $\mu$ surface mobility mechanism. Accordingly, at constant $R$, the lower $D_{\mathrm{s}}$ the higher the $\mathrm{d}^{2} c_{\mathrm{M}} / \mathrm{d} x^{2}$ value and, hence, the smaller the average diffusion layer associated with $\mathbf{M}$ atom surface diffusion. Therefore, the $\mathbf{M}-\mathbf{M}$ to $\mathbf{M}-\mathbf{S}$ domain surface rearrangement covers a continuous grading between two limiting situations, namely, atoms moving gradually from $\mathbf{M}-\mathbf{M}$ domains to border steps, as would be the case for $D_{s} \Rightarrow 0$, and a random fast spillover process for $D_{\mathrm{s}} \Rightarrow \infty$. This type of process is consistent with the surface diffusion-driven kinetic growth of atom layers on solids covering from generalized kink diffusion to random deposition with relaxation [45, 46].

Furthermore, for a given $\mathbf{M}$ at a constant $v$, the formation of $\mathrm{M}-\mathrm{S}$ domains is enhanced as $R$ is increased. On the other hand, for a different $M$, it appears that soft $M$ overlayers on $P t$ tend to produce preferentially a $\mathbf{M}-\mathbf{S}$ domain overlayer as $\mathbf{M}$ atoms spill over from either $\mathbf{M}-\mathbf{M}$ or $\mathbf{M}-\mathbf{S}$ domains to reach uncovered substrate areas more easily. This means that soft, low $T_{\mathrm{m}}$ metals favour a $2 \mathrm{D}$ rather than a $3 \mathrm{D}$ growth process, in contrast with hard, high $T_{\mathrm{m}}$ metals. However, in the early stages of growth $3 \mathrm{D} \mathbf{M}-\mathbf{M}$ domains tend to form on smooth $\mathrm{Pt}$ rather than on columnar structured $\mathrm{Pt}$.

Table 3. Values of $D_{\mathrm{s}},\left\langle\Delta^{2} c_{\mathrm{M}} / \Delta x^{2}\right\rangle_{\Delta t}$ and $\mathrm{d}^{2} c_{\mathrm{M}} / \mathrm{d} x^{2}$ derived from Fick's equation for various electrodeposited $\mathrm{M}$ at $298 \mathrm{~K}$

\begin{tabular}{cccccc}
\hline & & $\begin{array}{c}v=5 \times 10^{-3} \mathrm{~V} \mathrm{~s}^{-1} \\
R=30\end{array}$ & $\begin{array}{c}v=2 \times 10^{-2} \mathrm{~V} \mathrm{~s}^{-1} \\
R=30\end{array}$ & $\begin{array}{c}v=2 \times 10^{-2} \mathrm{~V} \mathrm{~s}^{-1} \\
\text { Smooth Pt }\end{array}$ & $\begin{array}{c}v \Rightarrow \infty \\
R=30\end{array}$ \\
\cline { 3 - 6 } & $\begin{array}{c}D_{s} \\
\mathrm{~cm}^{2} \mathrm{~s}^{-1}\end{array}$ & $\begin{array}{c}\left\langle\Delta^{2} c_{\mathrm{M}} / \Delta x^{2}\right\rangle_{\Delta t} \\
\mathrm{~mol} \mathrm{~cm}{ }^{-4}\end{array}$ & $\begin{array}{c}\left\langle\Delta^{2} c_{\mathrm{M}} / \Delta x^{2}\right\rangle_{\Delta t 1} \\
\mathrm{~mol} \mathrm{~cm}^{-4}\end{array}$ & $\begin{array}{c}\left\langle\Delta^{2} c_{\mathrm{M}} / \Delta x^{2}\right\rangle_{\Delta t I} \\
\mathrm{~mol} \mathrm{~cm}^{-4}\end{array}$ & $\begin{array}{c}\mathrm{d}^{2} c_{\mathrm{M}} / \mathrm{dx}^{2} \\
\mathrm{~mol} \mathrm{~cm}^{-4}\end{array}$ \\
\hline $\mathrm{Mg}$ & $1.2 \times 10^{-3}$ & $9.3 \times 10^{-9}$ & $2.6 \times 10^{-8}$ & $8.2 \times 10^{-8}$ & $3.8 \times 10^{-8}$ \\
$\mathrm{Cd}$ & $2.7 \times 10^{-7}$ & $3.6 \times 10^{-5}$ & $1.1 \times 10^{-4}$ & $3.9 \times 10^{-4}$ & $1.6 \times 10^{-4}$ \\
$\mathrm{~Pb}$ & $2.5 \times 10^{-10}$ & $3.4 \times 10^{-2}$ & $1.1 \times 10^{-1}$ & $4.1 \times 10^{-1}$ & $1.6 \times 10^{-1}$ \\
$\mathrm{Ag}$ & $1.4 \times 10^{-14}$ & $2.3 \times 10^{2}$ & $7.0 \times 10^{2}$ & $3.6 \times 10^{3}$ & $1.2 \times 10^{3}$ \\
$\mathrm{Cu}$ & $6.9 \times 10^{-17}$ & $3.7 \times 10^{4}$ & $1.3 \times 10^{5}$ & $9.3 \times 10^{5}$ & $1.9 \times 10^{5}$ \\
\hline
\end{tabular}




\section{CONCLUSIONS}

The comparative study of the early stages of $\mathrm{Hg}$, $\mathrm{Cd}, \mathrm{Pb}, \mathrm{Ag}$ and $\mathrm{Cu}$ electrodeposition on columnar and smooth $\mathrm{Pt}$ electrodes under non-equilibrium conditions, allowed us to establish the contribution of surface atom diffusion to determine whether an overlayer in which $\mathbf{M}-\mathbf{S}$ or $\mathbf{M}-\mathbf{M}$ domains predominate. The $q_{\mathrm{M}-\mathrm{S}} / q_{\mathrm{M}-\mathrm{M}}$ charge ratio on Pt depends on $T_{\mathrm{m}}$ and $\Delta H_{\mathrm{s}}$, the melting temperature and the enthalpy of sublimation of bulk $\mathrm{M}$, the value of $R$, the roughness factor of the columnar $\mathrm{Pt}$ electrode, the solution composition, and the characteristics of the potential routine.

In this case, the kinetics of surface atom diffusion fulfils Fick's equation, and the $\mathbf{M}-\mathbf{M}$ domain to $\mathbf{M}-\mathbf{S}$ domain surface rearrangement covers a continuous grading from two limiting situations, namely, a border step displacement-controlled kinetics for $D_{\mathrm{s}} \Rightarrow 0$, and a random fast spillover process for $D_{\mathrm{s}} \Rightarrow$ $\infty$.

Acknowledgements-The authors thank the Consejo Nacional de Investigaciones Científicas y Técnicas (CONICET, Argentina) for giving financial support to this work.

\section{REFERENCES}

1. D. M. Kolb, in Advances in Electrochemistry and Electrochemical Engineering, Vol. 11, (Edited by H. Gerischer and C. Tobias), Wiley, New York (1978).

2. R. Adzič, in Advances in Electrochemistry and Electrochemical Engineering, Vol. 13, (Edited by H. Gerischer and C. Tobias), Wiley, New York (1984).

3. G. Kokkinidis, J. electroanal. Chem. 201, 217 (1986).

4. R. Adzič, in Modern Aspects of Electrochemistry, Vol. 21, Ch. 5, (Edited by J. O'M. Bockris, R. E. White and D. E. Conway), Plenum Press.

5. S. Szabó, Intern. Ret). Phys. Chem. 10, 207 (1991).

6. D. Alonzo and B. Scharifker, J. electroanal. Chem. 274, $167(1989)$.

7. D. Margheritis, R. C. Salvarezza, M. C. Giordano and A. J. Arvia, J. electroanal. Chem. 229, 327 (1989)

8. P. Ocón, P. Herrasti, C. Palacio, M. E. Vela, R. C. Salvarezza, L. Vázquez and A. J. Arvia, J. electroanal. Chem. 357, 339 (1993).

9. F. El Omar, R. Durand and R. Faure, J. electroanal. Chem. 160, 385 (1984).

10. R. C. Salvarezza, D. Vásquez Moll, M. C. Giordano and A. J. Arvia, J. electroanal. Chem. 213, 301 (1986).

11. B. Parajón Costa, J. Canullo, D. Vásquez Moll, R. C. Salvarezza, M. C. Giordano and A. J. Arvia, J. electroanal. Chem. 244, 261 (1988)

12. M. Breiter, Electrochim. Acta 34, 1119 (1989).

13. R. C. Salvarezza and A. J. Arvia, Electrochim. Acta 33, 1031 (1988).

14. M. E. Martins, R. C. Salvarezza and A. J. Arvia, Electrochim. Acta 36, 1617 (1991).

15. M. E. Martins, R. C. Salvarezza, J. M. Vara and A. J. Arvia, J. electrochem. Soc. 138, 2509 (1991).

16. M. E. Martins, R. C. Salverezza and A. J. Arvia, Electrochim. Acta 37, 2203 (1992).

17. M. E. Martins, A. Hernández Creus, R. C. Salvarezza and A. J. Arvia, J. electroanal. Chem. 375, 141 (1994).

18. A. Chialvo, W. E. Triaca and A. J. Arvia, J. electroanal. Chem. 146, 93 (1983).
19. L. Vázquez, J. Gómez, A. M. Baró, N. García, M. L. Marcos, J. González Velasco, J. M. Vara, A. J. Arvia, J. Presa, A. Garcia and M. Aguilar, J. Am. chem. Soc. 109, 1731 (1987)

20. L. Vázquez, A. Bartolomé, A. M. Baró, C. Alonso, R. C. Salvarezza and A. J. Arvia, Surf. Sci. 215, 171 (1989).

21. C. Alonso, R. C. Salvarezza, J. M. Vara, A. J. Arvia, L. Vázquez, A. Bartolomé and A. M. Baró, J. electrochem. Soc. 137, 2161 (1990).

22. J. Zerbino, C. L. Perdriel and A. J. Arvia, Thin Solid Films 232, 63 (1993).

23. R. O. Lezna, N. R. de Tacconi, C. L. Perdriel and A. J. Arvia, in Proc. Symp. Electrochem. Soc. on Electrode Materials (Edited by S. Srinivasan, S. Wagner and $\mathbf{H}$. Wroblova), p. 31, The Electrochemical Society, Pennington, $N J(1987)$.

24 M. M. Gómez, L. Vázquez, R. C. Salvarezza, J. M. Vara and A. J. Arvia, J. electroanal. Chem. 125, 317 (1991).

25. S. G. Real, J. R. Vilche and A. J. Arvia, J, electroanal. Chem. 341, 181 (1992).

26. S. Trasatti and O. A. Petrii, Pure Appl. Chem. 63, 711 (1991).

27. Handbook of Chemistry and Physics, 73rd edition, (Edited by D. R. Lide), CRC Press, Boca Raton (1993).

28. J. Bénard in Adsorption on Metal Surfaces. Studies in Surface Science and Catalysis, Vol. 13, Elsevier Publishing Company (1983).

29. J. R. Galvele, J. electrochem. Soc. 133, 953 (1986); Corros. Soc. 27, 1 (1987).

30. A. J. Arvia, R. C. Salvarezza and J. M. Vara, Electrochim. Acta 37, 2155 (1992).

31. J. M. Doña and J. González Velasco, Surf. Sci. 274, 205 (1992).

32. N. A. Gjostein in Surfaces and Interfaces, Vol. I (Edited by J. J. Burke, N. L. Reed and V. Weiss), Syracuse University Press (1967).

33. H. P. Bonzel in Surface Physics of Materials (Edited by J. M. Blakely), Academic Press, New York (1975).

34. R. C. Salvarezza, J. M. Vara and A. J. Arvia, in preparation.

35. International Critical Tables, Vol. I, p. 103, McGrawHill, New York and London (1927).

36. H. Bort, K. Jüttner, W. J. Iorenz, G. Staikov and B. Budevski, Electrochim. Acta 28, 985 (1983) and references therein.

37. T. Chierchie, C. Mayer, K. Jüttner and W. J. Lorenz, J. electroanat. Chem. 191, 401 (1985).

38. T. Vitanov, A. Popov, G. Staikov, E. Budevski, W. J. Lorenz and E. Schmidt, Electrochim. Acta 31, 981 (1986).

39. W. J. Lorenz, L. M. Gassa, U. Schmidt, W. Obretenov, G. Staikov, V. Bostanov and E. Budevski, Electrochim. Acta 37, 2173 (1992).

40. W. Obretenov, U. Schmidt, W. J. Lorenz, G. Staikov, E. Budesvski, D. Carnal, U. Müller, H. Siegenthaler and E. Schmidt, J. electrochem. Soc. 140, 692 (1993) and references therein.

41. Encyclopedia of the Electrochemistry of the Elements (Edited by A. J. Bard), Vols. I.4 (Cd), 1.5 (Pb), II.6 (Cu), VIII.I (Ag), IX.A.1 (Hg), Marcel Dekker, New York (1976).

42. G. Erlich, Surf. Sci. 299/300, 628 (1994).

43. W. Jost, Diffusion in Solids, Liquids and Gases, Academic Press, New York (1955).

44. K. J. Vetter, Electrochemical Kinetics, p. 285. Academic Press, New York (1967).

45. P. I. Tamborenea and S. Das Sarma, Phys, Rev. E 48, 2575 (1993).

46. S. Das Sarma and S. V. Ghaisas, Phys. Rev. Lett. 69, 3762 (1992). 